\title{
Master's in Autonomous Systems: An Overview of the Robotics Curriculum and Outcomes at ISEP, Portugal
}

\author{
Eduardo Silva, José Almeida, Alfredo Martins, João Paulo Baptista, and Betina Campos Neves
}

\begin{abstract}
Robotics research in Portugal is increasing every year, but few students embrace it as one of their first choices for study. Until recently, job offers for engineers were plentiful, and those looking for a degree in science and technology would avoid areas considered to be demanding, like robotics. At the undergraduate level, robotics programs are still competing for a place in the classical engineering graduate curricula. Innovative and dynamic Master's programs may offer the solution to this gap. The Master's degree in autonomous systems at the Instituto Superior de Engenharia do Porto (ISEP), Porto, Portugal, was designed to provide a solid training in robotics and has been showing interesting results, mainly due to differences in course structure and the context in which students are welcomed to study and work.
\end{abstract}

Index Terms-Autonomous systems, curriculum, graduate research, Master's degree, robotics.

\section{INTRODUCTION}

IN PORTUGAL, as in many other countries, students con- sider degrees that involve science, technology, engineering, athematics (STFEA ) as being hard, discouraging, and too

difficult; they therefore avoid choosing them. Although robotics has been gathering huge numbers of fans in Portugal for over a decade now, and despite robotics R\&D producing important results as well as attracting those fans [1], Portuguese robotics education still requires new approaches in curricular offerings. Outreach in and teaching robotics have been fostered by Portuguese R\&D groups, engineering faculties, and polytechnic engineering schools [1]. In the recent European economic turmoil, more students began choosing STEM-related degrees since these are a synonym for sure job offers for new graduates. The way that graduate robotic education is presently offered has helped change minds and mold choices. Since it is difficult at the undergraduate level to implement the changes necessary to incorporate robotics adequately in the classical curriculum [2], the option is to offer a Master's program that remedies that lack of information and training.

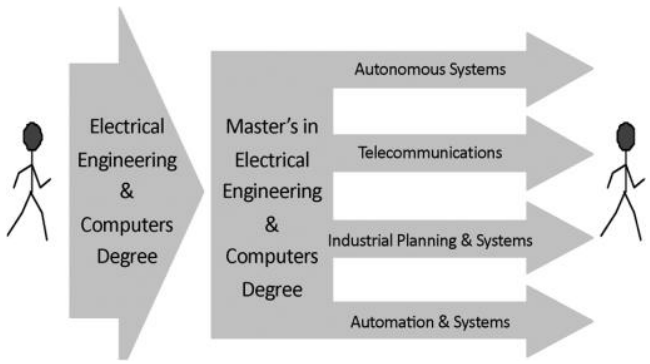

Fig. 1. Tracks in ISEP's electrical engineering and computers program.

At the Instituto Superior de Engenharia do Porto (ISEP), Porto, Portugal, neither the Electrical and Computer Engineering degree program nor other programs such as $\mathrm{Me}$ chanical Engineering to Computer Science Engineering had enough courses addressing robotic issues; all followed a more classical structure. This lack of robotics had to be remedied, so as to attract and challenge students, to prepare them in
the robotics area and to offer them new and innovative fields

for future work. Major universities in Europe and the US offer programs equivalent to that presented here. In most of these, the methodology was characterized by strong links to research laboratories and the business world, where the application of robotic systems is essential. Integrating this type of education within society is supported by specialized centers of excellence in robotics and autonomous systems. Among the most noteworthy of these are the Robotics Institute at Carnegie Mellon University (CMU), Pittsburgh, PA [3], which among several other options offers two Master's programs in robotics (in Robotic Systems Development of Science and in Robotic Technology), and the University of Pennsylvania, Philadelphia, PA, with its General Robotics, Automation, Sensing and Perception (GRASP) Lab [4] that offers its own Master's program in Robotics. European institutions offering Robotics and Autonomous Systems Master's programs linked to industry and integrating research activities include the Fraunhofer Institute, Munich, Germany, and Bonn-Rhein-Sieg University of Applied Sciences, Sankt Augustin, Germany [5], the Autonomous Systems Lab at École Polytechnique Fédérale de Lausanne, Lausanne, Switzerland [6], and the Autonomous Systems Lab of ETH, Zurich, Switzerland [7]. ISEP's Master's in Autonomous Systems (MAS) degree was designed to follow a similar strategy and incorporate approaches that are innovative for Portugal.

This MAS degree, designed to be totally devoted to robotics, is one of four tracks on ISEP's Electrical and Engineering and Computers Master's program, as structured after the Bologna 


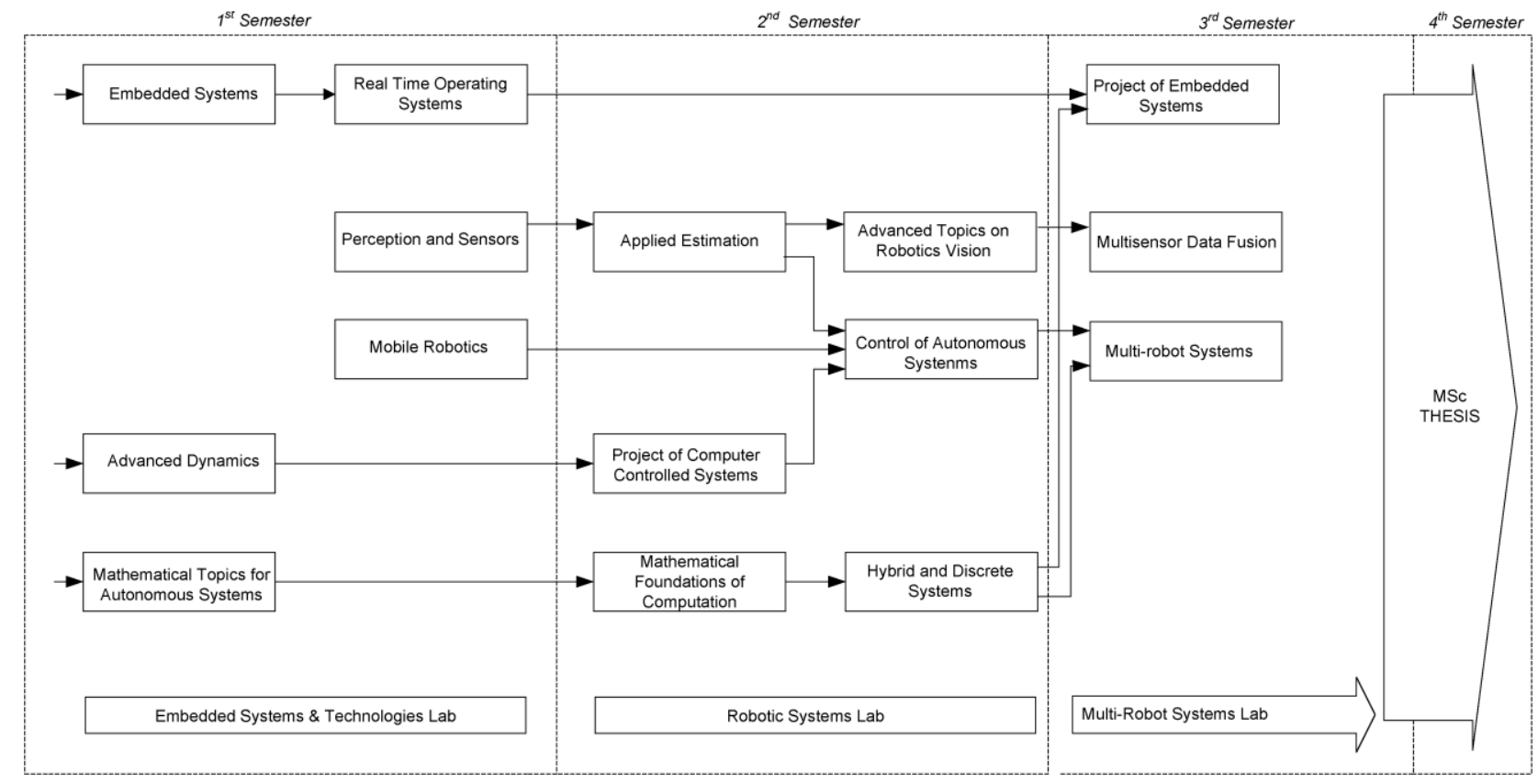

Fig. 2. Master's in autonomous systems: course curricular overview.

process reforms, as shown in Fig. 1. Although the Master's in Automation and Systems track has some optional robotics and robotics-related courses, it does not meet the goal of being a training entirely committed to robotics.

\section{MAS PROGRAM STRUCTURE}

The main goal of the MAS program is to fully prepare graduate students to design complex multirobot systems and/or to integrate robotic systems or embedded systems in the most diverse scenarios. The MAS is open to graduate students from an electrical, mechanical, or computer science background.

Fig. 2 summarizes the four-semester MAS curriculum, comprising courses, an internship (not shown), and a Master's dissertation thesis. In parallel with these mandatory courses, each of the first three semesters has a mandatory lab integrator course as well as a number of optional courses, each of which is part of the MAS program, that requires persistent work and takes no longer than a half-semester. For the first two semesters, the student take a maximum of three optional courses at any one time and a maximum of six optional courses per semester.

In addition, by the end of the second semester/beginning of the third, the student must do a six-week internship in a company or research lab. This is intended to expose the student to real-world engineering problems and foster innovative, entrepreneurial, and organizational aptitudes. The final, fourth semester is totally dedicated to the Master's thesis.

The MAS program is organized in four scientific subareas: Foundations in Maths and Physics, Embedded and Real Time Systems, Control, and Perception. Fig. 3 presents these four subareas, their place within the MAS curriculum, and the knowledge imparted. This structure is intended to convey the technical and scientific developments in applications of field robotics in areas such as safety and monitoring, water management, oceans, and the environment (climate change and pollution).

The mandatory courses permit students to develop a more autonomous and self-learning approach to project design and problem solving. The optional courses are an excellent means to

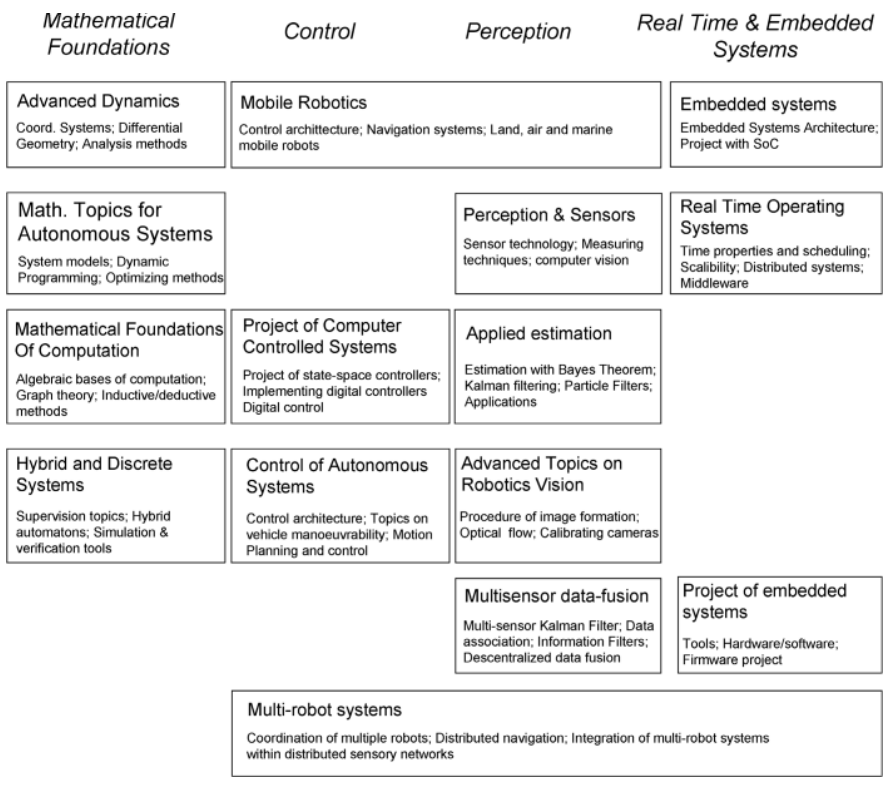

Fig. 3. Optional courses in the four MAS scientific subareas.

provide the student with the fundamental scientific knowledge underlying research topics and organizing it according to those four basic scientific subareas.

All the MAS's classes and lab work take place inside the Autonomous System R\&D Laboratory's new building, shown in Fig. 4. The Autonomous System Lab is now part of the INESC $\mathrm{TEC}^{1}$ Robotics' unit strongly contributing to form one of the largest R\&D robotics' consortia in Portugal.

The new standalone building benefits students by integrating them within the R\&D projects; they can spend their time (classes, work, projects, etc.) in the lab, in a dynamic and stimulating environment. In the R\&D facilities are classrooms,

${ }^{1}$ INESC TEC-Institute of Engineering. and Computer Systems-Technology and Science 

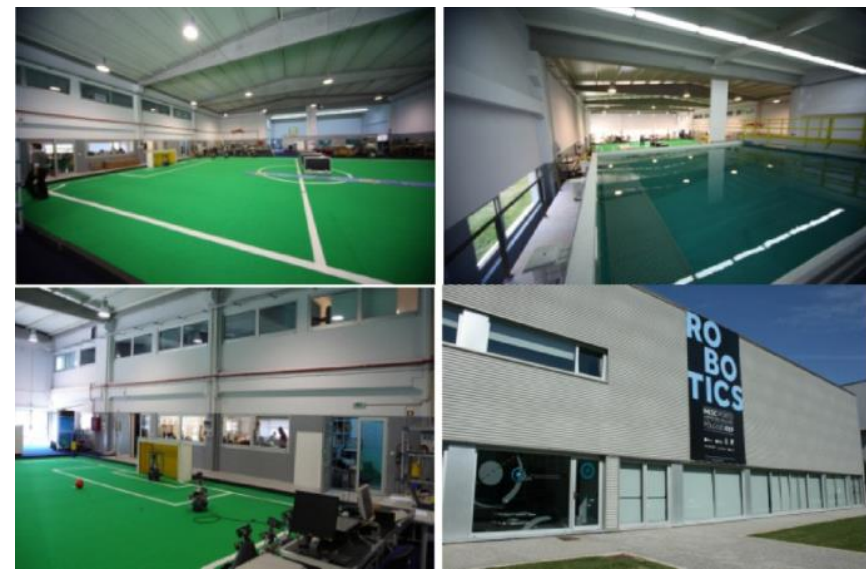

Fig. 4. Space layout inside the laboratory: (left) soccer field; (right) test tank and other work areas. Classrooms are located in the first floor. Researchers work together in an open space area next to the workshop, storage, and soldering rooms.
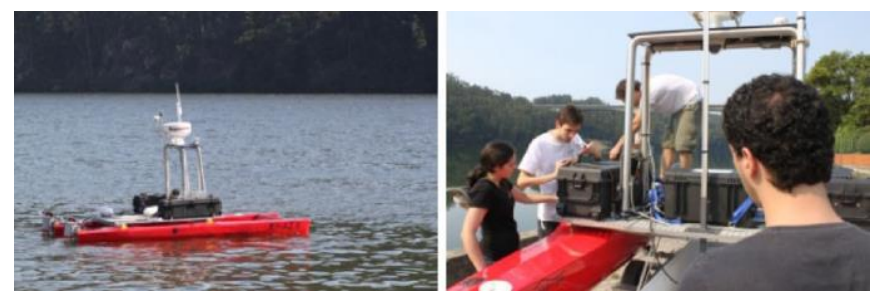

Fig. 5. (left) ROAZ on a field mission. (right) Students and researchers working on the mission.

labs, tools and a workshop, a water tank for testing remotely operated vehicles (ROVs) and other underwater vehicles, a robotic soccer field along with the locally developed robotic soccer team, a proper setup for indoor flight testing, and also many other types of robots and prototypes, with which the students have the opportunity to work. The MAS program follows a directed constructionism approach [8], in a project-based learning environment, and is supported by three main guidelines:

- to use robotics both as a learning process and as a demonstration tool for technologies and concepts;

- to support the learning process by merging the study of the fundamental basic problems with the research strategies of all of ISEP's R\&D resident groups;

- to encourage the support of relevant knowledge in the light of innovation and entrepreneurship.

The proposed methodology allows graduate students to deal with technological requirements, scientific knowledge, and realworld experiences by sharing opportunities with researchers, engineers, and undergraduate students in the same framework.

Some of the most important prototypes developed at the laboratory, and available to the students, are the robots ROAZ, GRIFO, and the ISEP soccer team-ISePorto-robots.

The ROAZ (Fig. 5) Autonomous Surface Vehicle (ASV) research program focuses on marine robotic systems, namely design issues in autonomous surface robots, navigation and control problems, multiple (and eventually heterogeneous) robot coordination, and environmental perception questions [9].

The FALCOS/GRIFO unmanned aerial vehicle (UAV) systems, shown in Fig. 6, were developed for low-altitude, mainly

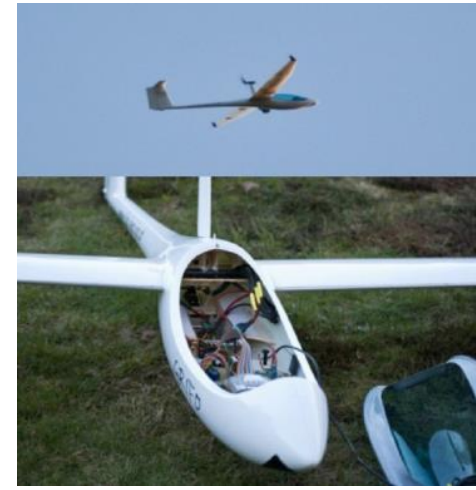

Fig. 6. FALCOS and GRIFO UAVs.

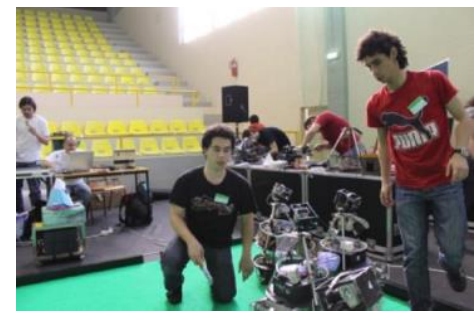

Fig. 7. ISEPORTO soccer team: researchers and students working together.

civilian applications such as forest fire prevention, safety, environmental monitoring, or aerial imagery. A set of fixed-wing (less than 4-m wingspan) UAVs with electrical propulsion was developed and performed multiple missions in test and operational scenarios. On-board image processing for fire detection was developed and tested with the cooperation of forest producers' associations [10].

The ISePorto Robotic Soccer Team, shown in Fig. 7, is part of an LSA-ISEP robotic football initiative and is designed for participation in Robocup Middle Size League (F2000). The two objectives behind the team formation are to provide an adequate testbed and case study for research in the authors' areas of interest and to develop a relevant application with educational purposes. The robotic football team provides an excellent tool to develop and demonstrate research in the areas of interest associated with autonomous systems, which are mainly sensor fusion, mobile robotics navigation, nonlinear hybrid feedback control, and coordination [11].

Generally, each optional course is taught in seven or eight 5-h sessions, over a seven-week or half-semester period during which each course has its specific day of the week.

The MAS is taught from 18:00 to 23:30 (6-11:30 p.m.), with a 30-min break for dinner, allowing working graduate students to attend after their day's work is over. Each session consists of the following:

- a 2-h lecture on some relevant topic (sometimes students are asked to give a short presentation on some topic fostering autonomous research skills);

- $1 \mathrm{~h}$ for the students to work autonomously, but with supervision, on the lecture topic;

- $2 \mathrm{~h}$ for the students to work actively on the topic of that day, by producing an analysis and/or report or by implementing some other type of related work (programming, problem solving/calculus).

Students are evaluated on three elements: "homework," set curricular work, and an exam. The teacher acts not just as a 

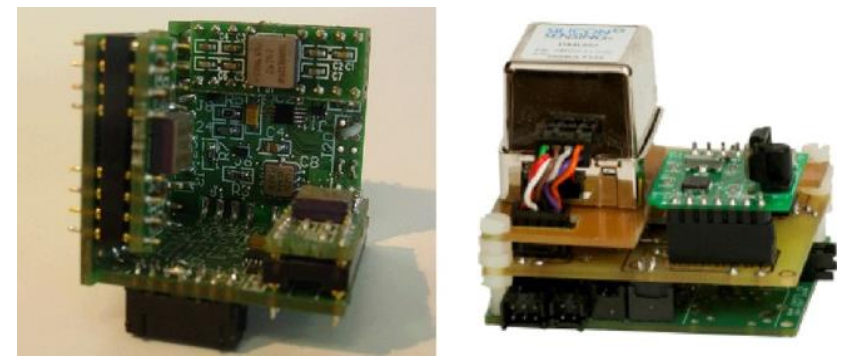

Fig. 8. Inertial navigation system developed by MAS students.

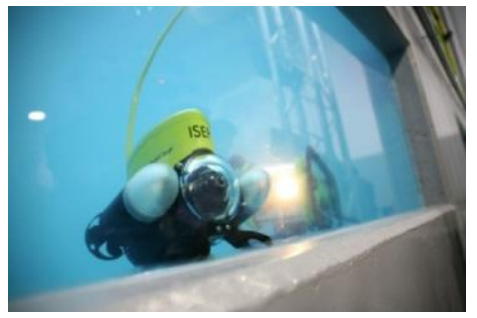

Fig. 9. Two ROV systems upgraded by MAS students.

knowledge facilitator and leader, but also assumes the role of a mentor, organizing the students' activities, and helping them acquire new skills through developing solutions to problems.

In this self-learning process, students use, in addition to the technical documentation associated with each robotic system, theses and monographs developed in the robotics unit of INESC TEC, as well as textbooks in the area of field robotics such as Probabilistic Robotics by Thrun [12] or Robotics Vision and Control by Corke [13].

\section{MANDATORY LAB COURSES}

The mandatory Embedded Systems and Technologies' Lab, run in the first semester, shown in Fig. 1, teaches students how to carry out a project by starting from specified elements and defined prerequisites and using advanced technologies. The particular problem they are given to solve addresses one particular science area. Examples of projects include students having to develop inertial units, embedded vision sensors, motion control systems, and distribution information systems. They thus learn how to develop elements of very dominant technologies.

The Robotics Systems' Lab, in the second semester, is intended to inculcate the students' ability to carry out a project once the problem has been defined. They have to develop methods to produce the correct specifications and definitions, and then have to define the technology and the scientific elements to be used; this should foster interdisciplinary mechanisms. For example, students usually have to develop modules, as in Fig. 8, to be applied in various types of robots (aerial, terrestrial or underwater) or, more specifically, navigation and control systems.

The Multirobot Systems Lab, in the third semester, is focused on developing the ability to create systems, such as those in Fig. 9, in which cooperation and coordination are critical to solving the problem. Also in this lab course, it is of the utmost importance to introduce the students to communication mechanisms as a basic issue. An example of this is students being expected to develop applications using multiple robots or systems (e.g., distributed sensor networks).

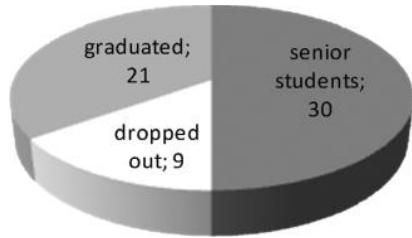

Fig. 10. Number of graduates, dropouts, and remaining senior students out of the total enrollment since 2007.

\section{MAS IN METRICS}

The way in which the MAS has been organized and run since September 2007 has emphasized the development of student attributes such as creativity, teamwork, willingness to learn, the ability to do project work, the autonomy to grasp and solve problems, a proactive attitude, the use of robotic systems both as an instrument and object of study that increases these attributes, and fostering the $R \& D$ element in the learning process as a key factor for innovation.

In its first year, the MAS had 14 students, all male. Of these 14 students, two are currently engineering teachers at ISEP and researchers in the Autonomous System Lab, six others are researchers at the Autonomous System Lab/INESC TEC, and the remaining six work in small- and medium-size enterprises in MAS-related areas.

Since inception, the MAS has had a total of 60 new enrolled students; only three of these were women, two of whom dropped out. Fig. 11 shows the evolution of the students' numbers from 2007 up to 2011 and includes expected graduate numbers for 2012 and 2013. The number of women versus men depicts a high imbalance that is less severe in other Electrical Engineering programs, Master's programs included. The Erasmus ${ }^{2}$ students earn equivalent grades, in their home countries, for their MAS Master's work. Their graduate numbers are included in Fig. 10 among the total number of graduates since the MAS started. Among these graduates, five are enrolling in (or have started) Ph.D. programs.

\section{FINAL REMARKS}

Although Europe has been in economic turmoil since 2008 - and Portugal presents one of the more complex scenarios of this turmoil - the majority of MAS graduates managed to find work easily until 2011. Recently, this has become harder. The MAS classes take place in late afternoon and evening, and the majority of the students are working. This dual role of study and work for MAS students has led to an increase in time to graduation, that often exceeds the four semesters of the curriculum. This takes a heavier toll on women, who tend to drop out more easily, especially if they have young children or family responsibilities. This issue requires strong attention in future strategies toreduce the genderimbalance.

The years to come will probably present great challenges to robotics education since the frail European economic situation has started to make itself felt in the academic context; one of the first signs to note is a decrease in student numbers. Cautious behavior on the part of mainstream industry has also started to narrow working possibilities; this also reflects on the choices

\footnotetext{
${ }^{2}$ The EuRopean Community Action Scheme for the Mobility of University Students (Erasmus) Programme is a European Union (EU) student exchange program.
} 


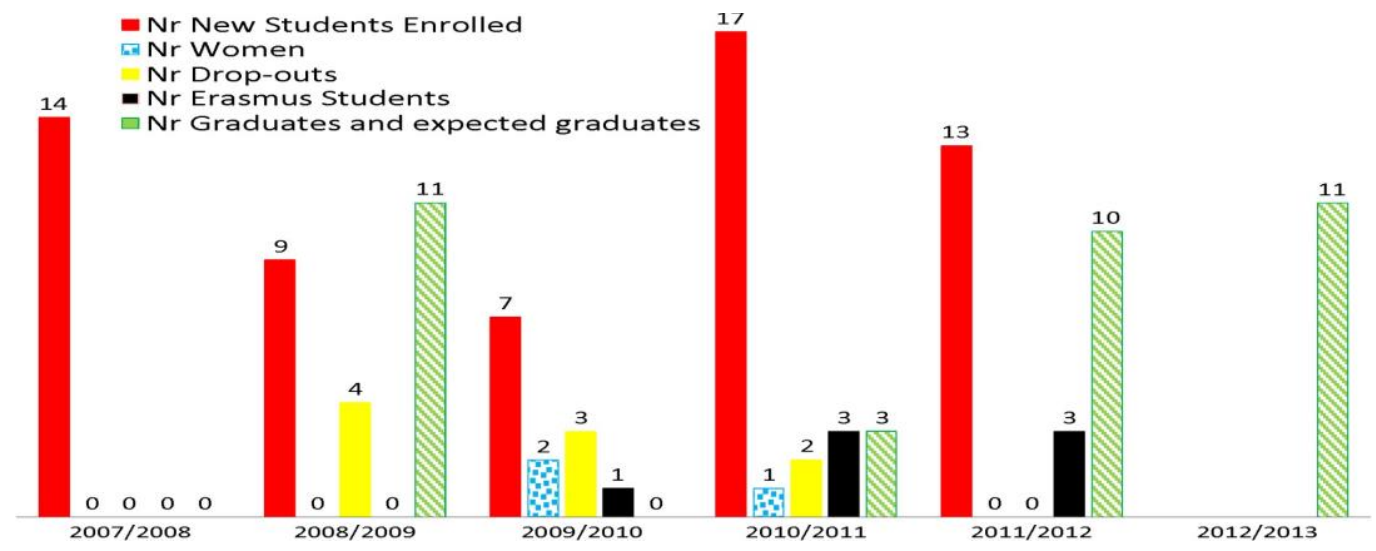

Fig. 11. Number of new enrollments per year versus number of women, dropouts, Erasmus students, graduates, and expected (near) future graduates.

and relations between the academic community, R\&D, and the industry. Nevertheless, the small- and medium-size technological enterprises and related industry that have been working with the authors are eager to have more MAS-skilled graduates, so it is feasible to improve those companies' competitiveness in this booming high-tech market. This is especially relevant in the area of the environment, and particularly the oceans, in which Portugal has unprecedented advantages and experience.

This will definitely enhance the search for innovative approaches to robotics education in Portugal.

\section{REFERENCES}

[1] P. Lima, "Robotics educational activities in Portugal: A motivating experience," IEEE Robot. Autom. Mag., vol. 14, no. 2, pp. 16-17, Jun. 2007.

[2] E. Welton, S. Hutchinson, and M. Spong, "A modular, interdisciplinary approach to undergraduate robotics education," in Proc. Frontiers Educ. Conf., 1993, pp. 714-719.

[3] Carnegie Mellon University, Pittsburgh, PA, "The Robotics Institute," Accessed Aug. 2012 [Online]. Available: http://www.ri.cmu.edu/ ri_static_content.html?menu_id=273

[4] University of Pennsylvania, Philadelphia, PA, "Robotics Master's program," Accessed Aug. 2012 [Online]. Available: http:// www.seas. upenn.edu/prospective-students/graduate/masters/ masters-robotics.php

[5] Bonn-Rhein-Sieg University of Applied Sciences, Sankt Augustin, Germany, "Master's program in autonomous systems," Accessed Aug. 2012 [Online]. Available: http://www.fh-bonn-rhein-sieg. de/fhbrsmedia/Downloads/studienberatung/flyer/Flyer+Master/ Flyer_Autonomous+Systems.pdf

[6] EPFL, Lausanne, Switzerland, "Robotics and autonomous systems," Accessed Aug. 2012 [Online]. Available: http://sti.epfl.ch/page1689-en.html

[7] ETH Zurich, Zurich, Switzerland, "Master in robotics systems and control," Accessed Aug. 2012 [Online]. Available: http://www.masterrobotics.ethz.ch/news/Master_Program_and_Tutors_2011.pdf

[8] M. Rosenblatt and H. Chosen, "Designing and implementing hands-on robotics lab," IEEE Intell. Syst., vol. 15, no. 6, pp. 32-39, Nov.-Dec. 2000.

[9] H. Ferreira, C. Almeida, A. Martins, J. Almeida, N. Dias, A. Dias, and E. Silva, "Autonomous bathymetry for risk assessment with ROAZ robotic surface vehicle," in Proc. IEEE OCEANS, May 2009, pp. 1-6.

[10] A. Martins, J. Almeida, A. B. Figueiredo, H. Silva, and E. Silva, "Vision based autonomous surface vehicle and autonomous aerial vehicle relative positioning and cooperation," in Proc. NATO AVT Symp. Platform Innov. Syst. Integr. Unmanned Air, Land Sea Veh., Florence, Italy, May 2007, pp. 33.1-33.18.

[11] H. Silva, J. M. Almeida, L. Lima, A. Martins, and E. P. Silva, "A real time vision system for autonomous systems: Characterization during a middle size match," in RoboCup 2007: Robot Soccer World Cup XI Lecture Notes in Computer Science. Berlin, Germany: Springer, Jul. 2008, vol. 5001/2008, pp. 504-511.
[12] S. Thrun, W. Burgard, and D. Fox, Probabilistic Robotics (Intelligent Robotics and Autonomous Agents). Cambridge, MA: MIT Press, 2005.

[13] P. I. Corke, Robotics, Vision \& Control. New York: Springer, 2011. 


\title{
Master's in Autonomous Systems: An Overview of the Robotics Curriculum and Outcomes at ISEP, Portugal
}

\author{
Eduardo Silva, José Almeida, Alfredo Martins, João Paulo Baptista, and Betina Campos Neves
}

\begin{abstract}
Robotics research in Portugal is increasing every year, but few students embrace it as one of their first choices for study. Until recently, job offers for engineers were plentiful, and those looking for a degree in science and technology would avoid areas considered to be demanding, like robotics. At the undergraduate level, robotics programs are still competing for a place in the classical engineering graduate curricula. Innovative and dynamic Master's programs may offer the solution to this gap. The Master's degree in autonomous systems at the Instituto Superior de Engenharia do Porto (ISEP), Porto, Portugal, was designed to provide a solid training in robotics and has been showing interesting results, mainly due to differences in course structure and the context in which students are welcomed to study and work.
\end{abstract}

Index Terms-Autonomous systems, curriculum, graduate research, Master's degree, robotics.

\section{INTRODUCTION}

$\mathbf{I}$ $\mathrm{N}$ PORTUGAL, as in many other countries, students conder degrees that involve science, technology, engineering, and mathematics (STEM) as being hard, discouraging, and too difficult; they therefore avoid choosing them. Although robotics has been gathering huge numbers of fans in Portugal for over a decade now, and despite robotics R\&D producing important results as well as attracting those fans [1], Portuguese robotics education still requires new approaches in curricular offerings. Outreach in and teaching robotics have been fostered by Portuguese R\&D groups, engineering faculties, and polytechnic engineering schools [1]. In the recent European economic turmoil, more students began choosing STEM-related degrees since these are a synonym for sure job offers for new graduates. The way that graduate robotic education is presently offered has helped change minds and mold choices. Since it is difficult at the undergraduate level to implement the changes necessary to incorporate robotics adequately in the classical curriculum [2], the option is to offer a Master's program that remedies that lack of information and training.

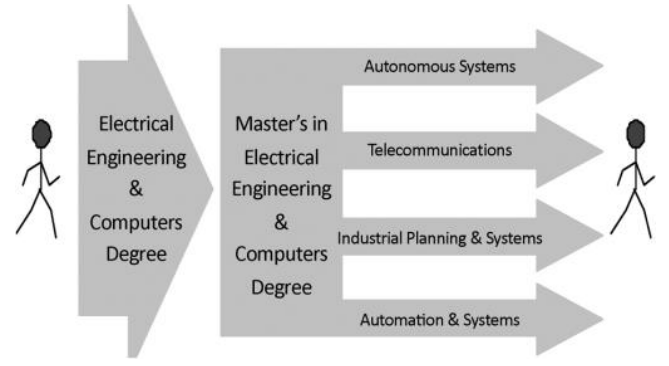

Fig. 1. Tracks in ISEP's electrical engineering and computers program.

At the Instituto Superior de Engenharia do Porto (ISEP), Porto, Portugal, neither the Electrical and Computer Engineering degree program nor other programs such as Mechanical Engineering to Computer Science Engineering had enough courses addressing robotic issues; all followed a more classical structure. This lack of robotics had to be remedied, so as to attract and challenge students, to prepare them in the robotics area and to offer them new and innovative fields for future work. Major universities in Europe and the US offer programs equivalent to that presented here. In most of these, the methodology was characterized by strong links to research laboratories and the business world, where the application of robotic systems is essential. Integrating this type of education within society is supported by specialized centers of excellence in robotics and autonomous systems. Among the most noteworthy of these are the Robotics Institute at Carnegie Mellon University (CMU), Pittsburgh, PA [3], which among several other options offers two Master's programs in robotics (in Robotic Systems Development of Science and in Robotic Technology), and the University of Pennsylvania, Philadelphia, PA, with its General Robotics, Automation, Sensing and Perception (GRASP) Lab [4] that offers its own Master's program in Robotics. European institutions offering Robotics and Autonomous Systems Master's programs linked to industry and integrating research activities include the Fraunhofer Institute, Munich, Germany, and Bonn-Rhein-Sieg University of Applied Sciences, Sankt Augustin, Germany [5], the Autonomous Systems Lab at École Polytechnique Fédérale de Lausanne, Lausanne, Switzerland [6], and the Autonomous Systems Lab of ETH, Zurich, Switzerland [7]. ISEP's Master's in Autonomous Systems (MAS) degree was designed to follow a similar strategy and incorporate approaches that are innovative for Portugal.

This MAS degree, designed to be totally devoted to robotics, is one of four tracks on ISEP's Electrical and Engineering and Computers Master's program, as structured after the Bologna 


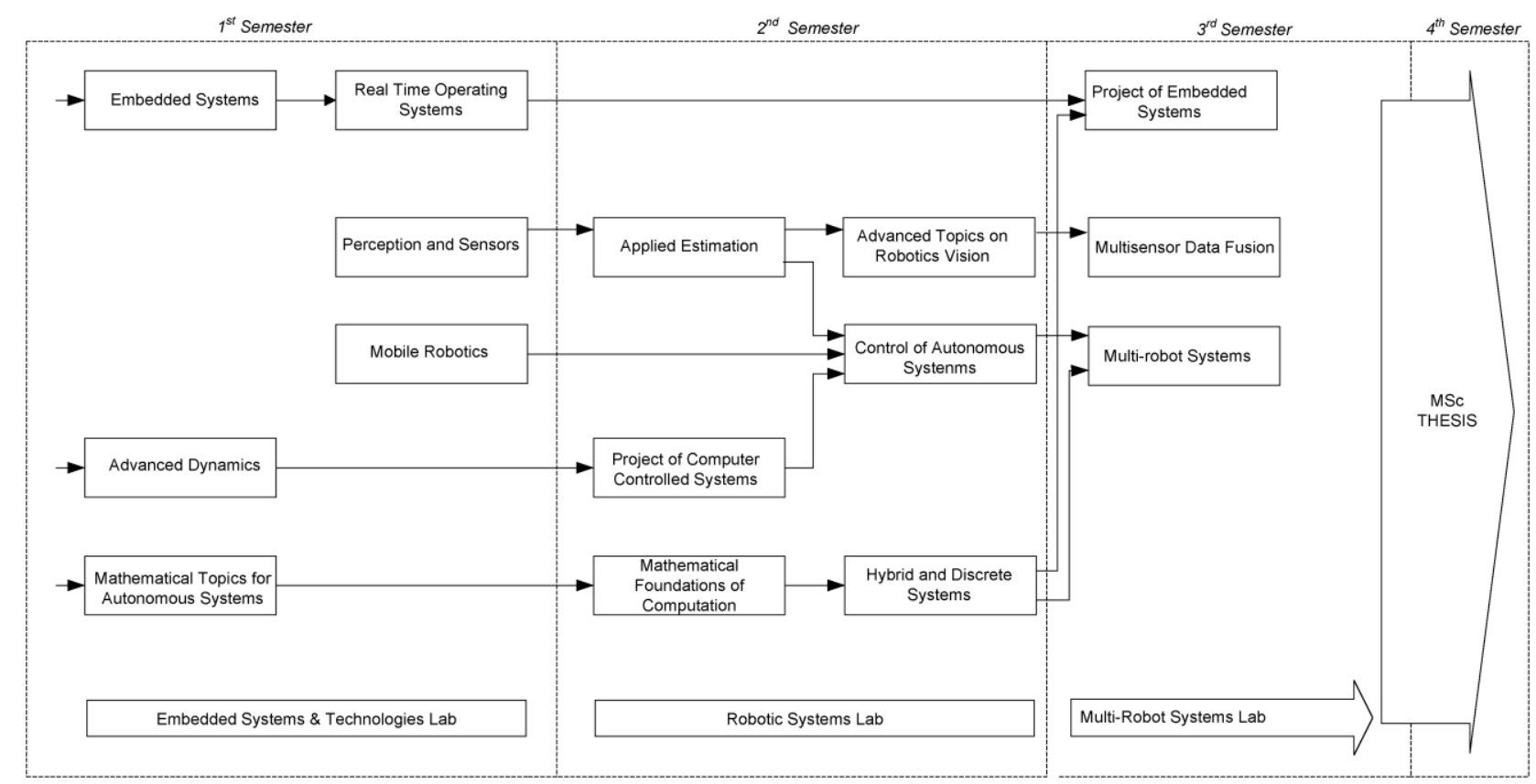

Fig. 2. Master's in autonomous systems: course curricular overview.

process reforms, as shown in Fig. 1. Although the Master's in Automation and Systems track has some optional robotics and robotics-related courses, it does not meet the goal of being a training entirely committed to robotics.

\section{MAS PRogram StRUCTURE}

The main goal of the MAS program is to fully prepare graduate students to design complex multirobot systems and/or to integrate robotic systems or embedded systems in the most diverse scenarios. The MAS is open to graduate students from an electrical, mechanical, or computer science background.

Fig. 2 summarizes the four-semester MAS curriculum, comprising courses, an internship (not shown), and a Master's dissertation thesis. In parallel with these mandatory courses, each of the first three semesters has a mandatory lab integrator course as well as a number of optional courses, each of which is part of the MAS program, that requires persistent work and takes no longer than a half-semester. For the first two semesters, the student take a maximum of three optional courses at any one time and a maximum of six optional courses per semester.

In addition, by the end of the second semester/beginning of the third, the student must do a six-week internship in a company or research lab. This is intended to expose the student to real-world engineering problems and foster innovative, entrepreneurial, and organizational aptitudes. The final, fourth semester is totally dedicated to the Master's thesis.

The MAS program is organized in four scientific subareas: Foundations in Maths and Physics, Embedded and Real Time Systems, Control, and Perception. Fig. 3 presents these four subareas, their place within the MAS curriculum, and the knowledge imparted. This structure is intended to convey the technical and scientific developments in applications of field robotics in areas such as safety and monitoring, water management, oceans, and the environment (climate change and pollution).

The mandatory courses permit students to develop a more autonomous and self-learning approach to project design and problem solving. The optional courses are an excellent means to

Mathematical
Foundations

Fig. 3. Optional courses in the four MAS scientific subareas.

provide the student with the fundamental scientific knowledge underlying research topics and organizing it according to those four basic scientific subareas.

All the MAS's classes and lab work take place inside the Autonomous System R\&D Laboratory's new building, shown in Fig. 4. The Autonomous System Lab is now part of the INESC TEC ${ }^{1}$ Robotics' unit strongly contributing to form one of the largest R\&D robotics' consortia in Portugal.

The new standalone building benefits students by integrating them within the $R \& D$ projects; they can spend their time (classes, work, projects, etc.) in the lab, in a dynamic and stimulating environment. In the $R \& D$ facilities are classrooms,

${ }^{1}$ INESC TEC-Institute of Engineering. and Computer Systems-Technology and Science 

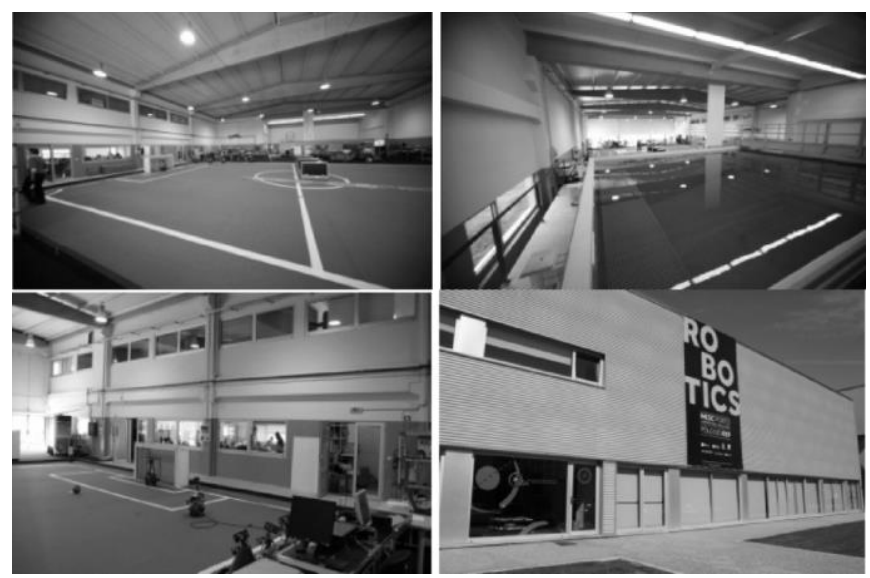

Fig. 4. Space layout inside the laboratory: (left) soccer field; (right) test tank and other work areas. Classrooms are located in the first floor. Researchers work together in an open space area next to the workshop, storage, and soldering rooms.
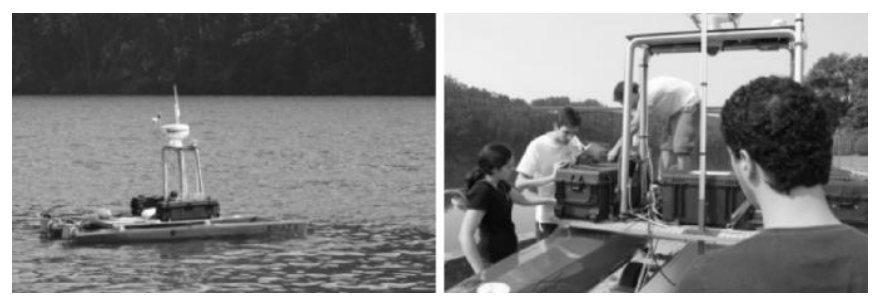

Fig. 5. (left) ROAZ on a field mission. (right) Students and researchers working on the mission.

labs, tools and a workshop, a water tank for testing remotely operated vehicles (ROVs) and other underwater vehicles, a robotic soccer field along with the locally developed robotic soccer team, a proper setup for indoor flight testing, and also many other types of robots and prototypes, with which the students have the opportunity to work. The MAS program follows a directed constructionism approach [8], in a project-based learning environment, and is supported by three main guidelines:

- to use robotics both as a learning process and as a demonstration tool for technologies and concepts;

- to support the learning process by merging the study of the fundamental basic problems with the research strategies of all of ISEP's R\&D resident groups;

- to encourage the support of relevant knowledge in the light of innovation and entrepreneurship.

The proposed methodology allows graduate students to deal with technological requirements, scientific knowledge, and realworld experiences by sharing opportunities with researchers, engineers, and undergraduate students in the same framework.

Some of the most important prototypes developed at the laboratory, and available to the students, are the robots ROAZ, GRIFO, and the ISEP soccer team-ISePorto-robots.

The ROAZ (Fig. 5) Autonomous Surface Vehicle (ASV) research program focuses on marine robotic systems, namely design issues in autonomous surface robots, navigation and control problems, multiple (and eventually heterogeneous) robot coordination, and environmental perception questions [9].

The FALCOS/GRIFO unmanned aerial vehicle (UAV) systems, shown in Fig. 6, were developed for low-altitude, mainly

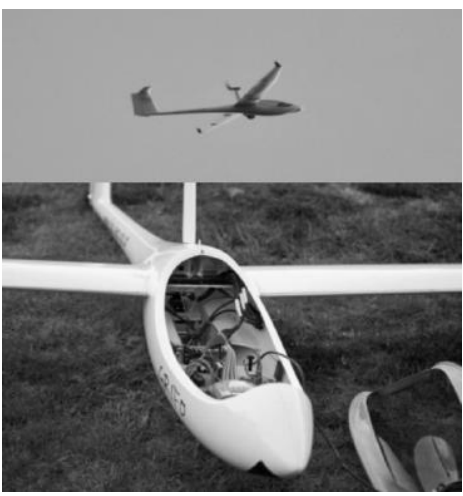

Fig. 6. FALCOS and GRIFO UAVs.

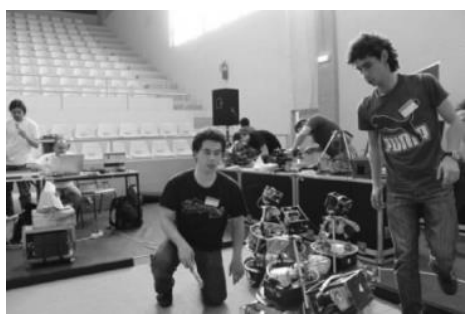

Fig. 7. ISEPORTO soccer team: researchers and students working together.

civilian applications such as forest fire prevention, safety, environmental monitoring, or aerial imagery. A set of fixed-wing (less than 4-m wingspan) UAVs with electrical propulsion was developed and performed multiple missions in test and operational scenarios. On-board image processing for fire detection was developed and tested with the cooperation of forest producers' associations [10].

The ISePorto Robotic Soccer Team, shown in Fig. 7, is part of an LSA-ISEP robotic football initiative and is designed for participation in Robocup Middle Size League (F2000). The two objectives behind the team formation are to provide an adequate testbed and case study for research in the authors' areas of interest and to develop a relevant application with educational purposes. The robotic football team provides an excellent tool to develop and demonstrate research in the areas of interest associated with autonomous systems, which are mainly sensor fusion, mobile robotics navigation, nonlinear hybrid feedback control, and coordination [11].

Generally, each optional course is taught in seven or eight 5-h sessions, over a seven-week or half-semester period during which each course has its specific day of the week.

The MAS is taught from 18:00 to 23:30 (6-11:30 p.m.), with a 30-min break for dinner, allowing working graduate students to attend after their day's work is over. Each session consists of the following:

- a 2-h lecture on some relevant topic (sometimes students are asked to give a short presentation on some topic fostering autonomous research skills);

- $1 \mathrm{~h}$ for the students to work autonomously, but with supervision, on the lecture topic;

- $2 \mathrm{~h}$ for the students to work actively on the topic of that day, by producing an analysis and/or report or by implementing some other type of related work (programming, problem solving/calculus).

Students are evaluated on three elements: "homework," set curricular work, and an exam. The teacher acts not just as a 

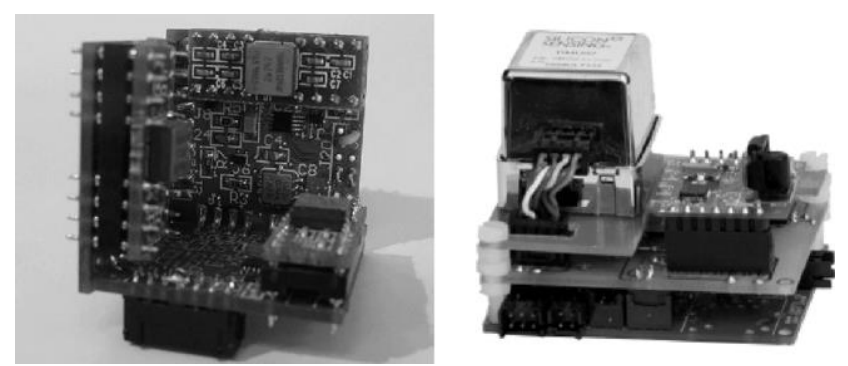

Fig. 8. Inertial navigation system developed by MAS students.

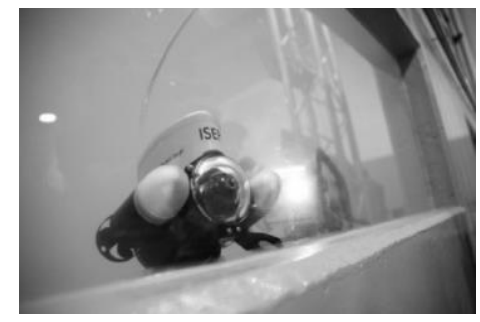

Fig. 9. Two ROV systems upgraded by MAS students.

knowledge facilitator and leader, but also assumes the role of a mentor, organizing the students' activities, and helping them acquire new skills through developing solutions to problems.

In this self-learning process, students use, in addition to the technical documentation associated with each robotic system, theses and monographs developed in the robotics unit of INESC TEC, as well as textbooks in the area of field robotics such as Probabilistic Robotics by Thrun [12] or Robotics Vision and Control by Corke [13].

\section{MANDATORy LAB COURSES}

The mandatory Embedded Systems and Technologies' Lab, run in the first semester, shown in Fig. 1, teaches students how to carry out a project by starting from specified elements and defined prerequisites and using advanced technologies. The particular problem they are given to solve addresses one particular science area. Examples of projects include students having to develop inertial units, embedded vision sensors, motion control systems, and distribution information systems. They thus learn how to develop elements of very dominant technologies.

The Robotics Systems' Lab, in the second semester, is intended to inculcate the students' ability to carry out a project once the problem has been defined. They have to develop methods to produce the correct specifications and definitions, and then have to define the technology and the scientific elements to be used; this should foster interdisciplinary mechanisms. For example, students usually have to develop modules, as in Fig. 8, to be applied in various types of robots (aerial, terrestrial or underwater) or, more specifically, navigation and control systems.

The Multirobot Systems Lab, in the third semester, is focused on developing the ability to create systems, such as those in Fig. 9, in which cooperation and coordination are critical to solving the problem. Also in this lab course, it is of the utmost importance to introduce the students to communication mechanisms as a basic issue. An example of this is students being expected to develop applications using multiple robots or systems (e.g., distributed sensor networks).

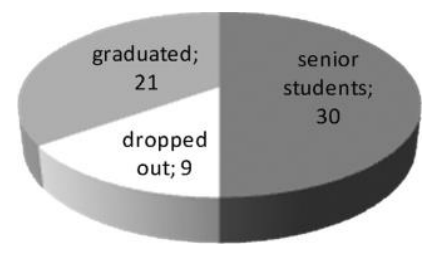

Fig. 10. Number of graduates, dropouts, and remaining senior students out of the total enrollment since 2007.

\section{MAS IN METRICS}

The way in which the MAS has been organized and run since September 2007 has emphasized the development of student attributes such as creativity, teamwork, willingness to learn, the ability to do project work, the autonomy to grasp and solve problems, a proactive attitude, the use of robotic systems both as an instrument and object of study that increases these attributes, and fostering the R\&D element in the learning process as a key factor for innovation.

In its first year, the MAS had 14 students, all male. Of these 14 students, two are currently engineering teachers at ISEP and researchers in the Autonomous System Lab, six others are researchers at the Autonomous System Lab/INESC TEC, and the remaining six work in small- and medium-size enterprises in MAS-related areas.

Since inception, the MAS has had a total of 60 new enrolled students; only three of these were women, two of whom dropped out. Fig. 11 shows the evolution of the students' numbers from 2007 up to 2011 and includes expected graduate numbers for 2012 and 2013. The number of women versus men depicts a high imbalance that is less severe in other Electrical Engineering programs, Master's programs included. The Erasmus ${ }^{2}$ students earn equivalent grades, in their home countries, for their MAS Master's work. Their graduate numbers are included in Fig. 10 among the total number of graduates since the MAS started. Among these graduates, five are enrolling in (or have started) Ph.D. programs.

\section{Final Remarks}

Although Europe has been in economic turmoil since 2008 - and Portugal presents one of the more complex scenarios of this turmoil - the majority of MAS graduates managed to find work easily until 2011. Recently, this has become harder. The MAS classes take place in late afternoon and evening, and the majority of the students are working. This dual role of study and work for MAS students has led to an increase in time to graduation, that often exceeds the four semesters of the curriculum. This takes a heavier toll on women, who tend to drop out more easily, especially if they have young children or family responsibilities. This issue requires strong attention in future strategies to reduce the gender imbalance.

The years to come will probably present great challenges to robotics education since the frail European economic situation has started to make itself felt in the academic context; one of the first signs to note is a decrease in student numbers. Cautious behavior on the part of mainstream industry has also started to narrow working possibilities; this also reflects on the choices

\footnotetext{
${ }^{2}$ The EuRopean Community Action Scheme for the Mobility of University Students (Erasmus) Programme is a European Union (EU) student exchange program.
} 


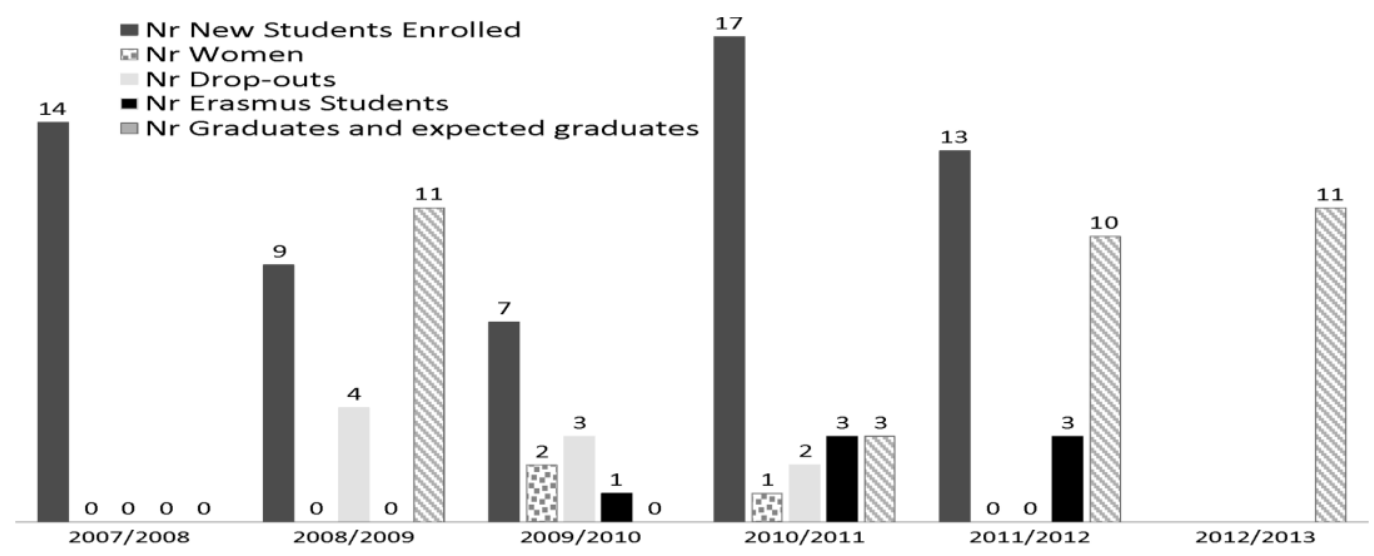

Fig. 11. Number of new enrollments per year versus number of women, dropouts, Erasmus students, graduates, and expected (near) future graduates.

and relations between the academic community, R\&D, and the industry. Nevertheless, the small- and medium-size technological enterprises and related industry that have been working with the authors are eager to have more MAS-skilled graduates, so it is feasible to improve those companies' competitiveness in this booming high-tech market. This is especially relevant in the area of the environment, and particularly the oceans, in which Portugal has unprecedented advantages and experience.

This will definitely enhance the search for innovative approaches to robotics education in Portugal.

\section{REFERENCES}

[1] P. Lima, "Robotics educational activities in Portugal: A motivating experience," IEEE Robot. Autom. Mag., vol. 14, no. 2, pp. 16-17, Jun. 2007.

[2] E. Welton, S. Hutchinson, and M. Spong, "A modular, interdisciplinary approach to undergraduate robotics education," in Proc. Frontiers Educ. Conf., 1993, pp. 714-719.

[3] Carnegie Mellon University, Pittsburgh, PA, "The Robotics Institute," Accessed Aug. 2012 [Online]. Available: http://www.ri.cmu.edu/ ri static content.html?menu id $=273$

[4] University of Pennsylvania, Philadelphia, PA, "Robotics Master's program," Accessed Aug. 2012 [Online]. Available: http:// www.seas. upenn.edu/prospective-students/graduate/masters/ masters-robotics.php

[5] Bonn-Rhein-Sieg University of Applied Sciences, Sankt Augustin, Germany, "Master's program in autonomous systems," Accessed Aug. 2012 [Online]. Available: http://www.fh-bonn-rhein-sieg. de/fhbrsmedia/Downloads/studienberatung/flyer/Flyer+Master/ Flyer_Autonomous+Systems.pdf

[6] EPFL, Lausanne, Switzerland, "Robotics and autonomous systems," Accessed Aug. 2012 [Online]. Available: http://sti.epfl.ch/page- 1689en.html

[7] ETH Zurich, Zurich, Switzerland, "Master in robotics systems and control," Accessed Aug. 2012 [Online]. Available: http://www.masterrobotics.ethz.ch/news/Master_Program_and_Tutors_2011.pdf

[8] M. Rosenblatt and H. Chosen, "Designing and implementing hands-on robotics lab," IEEE Intell. Syst., vol. 15, no. 6, pp. 32-39, Nov.-Dec. 2000.

[9] H. Ferreira, C. Almeida, A. Martins, J. Almeida, N. Dias, A. Dias, and E. Silva, "Autonomous bathymetry for risk assessment with ROAZ robotic surface vehicle," in Proc. IEEE OCEANS, May 2009, pp. 1-6. [10]

A. Martins, J. Almeida, A. B. Figueiredo, H. Silva, and E. Silva, "Vi- sion based autonomous surface vehicle and autonomous aerial vehicle relative positioning and cooperation," in Proc. NATO AVT Symp. Plat- form Innov. Syst. Integr. Unmanned Air, Land Sea Veh., Florence, Italy, May 2007, pp. 33.1-33.18.

[11] H. Silva, J. M. Almeida, L. Lima, A. Martins, and E. P. Silva, "A real time vision system for autonomous systems: Characterization during a middle size match," in RoboCup 2007: Robot Soccer World Cup XI Lecture Notes in Computer Science. Berlin, Germany: Springer, Jul. 2008, vol. 5001/2008, pp. 504-511.
[12] S. Thrun, W. Burgard, and D. Fox, Probabilistic Robotics (Intelligent Robotics and Autonomous Agents). Cambridge, MA: MIT Press, 2005.

[13] P. I. Corke, Robotics, Vision \& Control. New York: Springer, 2011. 